\title{
Health Education Manpower in the United States
}

\author{
Scott K Simonds, Dr.P.H.* \\ University of Michigan, School of Public Health
}

\begin{abstract}
Problems in collection of uniform data on health education manpower on a continuing basis are discussed. Sources of data on current health education manpower projections for future needs are reviewed Possible directions for improving manpower planning in this field are cited.
\end{abstract}

The issue of adequate health manpower is central to the continuing development of the health care system. Yet Butter has stated that "a review of health manpower statistics points to large volumes of certain types of data for a few established health professions and serious data gaps for practically all categories of health personnel."s Over the years, statistics on health manpower have been collected by several organizations for a variety of purposes, but as yet "no comprehensive and comparable data system on all types of health manpower has been developed. Differences in definitions, coverage, timing, and data collection methods have given rise to numerous problems of noncomparability among statistics."31 Health education manpower statistics are no exception to these problems. In fact, health education as an occupational category has had additional problems relating to its newness compared to most other occupations in the health care system; to its small size compared to the total occupational count in the health field; and to its constantly changing nature, in which different levels and types of preparation and practice have evolved rapidly to meet emerging needs for service.

Despite the fact that serious problems exist in determining present numbers and in projecting future health education manpower needs, there is much to be learned from a review of existing data that may be helpful in anticipating current and future requirements, if not precisely projecting supply and demand. This article, therefore, attempts to document and evaluate existing data on health education manpower and to suggest some trends and directions useful for manpower planning and for charting new manpower studies. It should be noted at the outset that data relating to school health education manpower has not been explored in depth, mainly due to its unavail-

\footnotetext{
* Professor of Health Education, of Health Behavior and Health Education, University of Michigan, School of Public Health, Ann Arbor, MI 48109.
} 
ability or inaccessibility. This omission is recognized as a serious one in planning for total health education manpower in the United States. However, despite the inherent limitations of the data, an effort has been made to account for the gross numbers of persons estimated to be working in the field of school health education and to consider their ranks in the total manpower picture.

\section{Health Education as an}

\section{Occupational Category and as a Profession}

A fundamental obstacle to collecting accurate and comparable data on health education manpower is an acceptable definition of the occupational category and the professional health educator. As an occupational specialty health education falls within category No. 171 of the U.S. Census, in a group with social and welfare workers.33 However, the Carnegie Commission on Higher Education has grouped health education specialists among the "high level" health care jobs (along with psychiatrists, neurologists, physicians, dentists, veterinarians, life scientists, podiatrists, biochemists, biophysicists, administrators of hospitals and other health institutions, clinical psychologists, optometrists, pharmacists, and sanitary engineers) in contrast to social workers who are classified by the Commission among the "middle level" jobs (along with dietitians, nutritionists, nurses, dental hygienists, sanitarians, speech and hearing therapists, and other related occupations.) $)^{6}$ For purposes of Federal statistics, health education is currently considered among the 32 major occupational groups in the health field and as such represents a continuing focus for manpower data collection at the national level.29

Health education as a profession is considered to have started in the United States with the graduate preparation of health educators at the Massachusetts Institute of Technology in 1921. However, an occupational grouping is not a profession, at least according to definitions of occupational sociologists, until it has a body of systematic theory; until its authority is recognized by a client group; until there is broad community sanction and approval of its authority; until there is a code of ethics; and until there is a professional culture sustained by formal association. It is recognized also that each occupational group striving for professional status goes through a number of steps to achieve that status, including application of full time activity to the task; establishment of university training; redefinition of core tasks so that less skilled tasks are given to subordinates; conflict between early visionaries and new professionals over standards and goals; conflict between new occupations and neighboring ones; and political agitation to gain legal protection. Nearly all occupational groups go through these steps on the way to becoming a profession. ${ }^{10,12,18,22}$ 
It is generally recognized that health education as an occupational group has gone through most of these steps. Yet to be accomplished are the development of a code of ethics, the codification of a body of theory, and the undertaking of political agitation to gain legal protection. Regarding the first, attempts have been made to consolidate and record a code of ethics, but this task persists as an item on the agenda of the professional organizations in the field. The second, a codified body of theory, has been even more difficult to attain since so much of the theory and research in health education evolves from the behavioral sciences which themselves have not been adequately codified. When the first major text on the application of the behavioral sciences in health education appears, it would be symbolic of the necessary professional step to codify the body of knowledge, based on theory and research, which health educators now accept and utilize. At present, there is virtually no discussion of record regarding the third item, agitation to gain legal protection. However, with the development of the clinical health education specialist and the possible legal ramifications of patient education practice, legal protection may become an issue for the profession. A movement towards professional certification, already underway in health education, may also lead to some sort of state level system to "protect" the practitioner and the consumer.

The traditional appellation for persons employed in health education has been health educator; however, "the term health education specialist has replaced the term health educator, (and) the term community health educator, used in the 1967 statement of the Society for Public Health Education is regarded as no longer appropriate." 21 The essential function of the health educator has always been to educate the general public regarding personal and community health matters and to assure that this function was done effectively by other disciplines in the health field.

With the rapid expansion of medical, scientific, and technical knowledge in the last couple of decades, the term "health educator" has also been used to describe someone whose main function is on-thejob training of health workers or the continuing education of health care providers. It is sometimes applied to persons employed as directors of training and education in hospitals. Indeed, in tertain professional settings, the term health education has come to mean continuing education of the health professions.

Currently there are three academic levels of preparation for individuals whose essential function is health education: baccalaureate, master's, and doctoral. In addition, however, positions have begun to be established within the health care system for individuals with less than baccalaureate preparation to carry out less complicated tasks in health education. Requirements for training 
programs for this group have been established.20

\section{Sources of Data On Health Education Mampower}

There is no single source of health education manpower data. A review of the literature shows that published health education manpower research has been undertaken primarily by Kent in a longitudinal study 16 to determine (a) annual numbers of master's-level graduates of schools of public health who have been active workers in public health education since 1944 and (b) distributions of their selective professional characteristics including geographical area, operational area, training rates, sex, attrition, and salaries. Sliepcevich documented in 1970 institutions offering programs of specialization in health education at undergraduate and graduate levels and in schools of public health ${ }^{25}$ which was followed by another

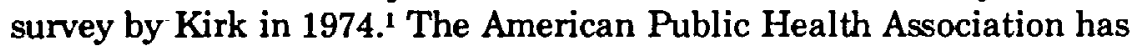
made available data on numbers of graduates in programs of public health education in schools of public health accredited by APHA and has provided other relevant data arising from committee reports, usually unpublished. Other existing data are estimates of personnel employed in health education work as determined and reported by professional organizations including the Society for Public Health Education, the American School Health Association, and the American Alliance for Health, Physical Education and Recreation. Other published sources of incidental or related information are from divisions of the U.S. Public Health Service, doctoral dissertations, testimony before the President's Committee on Health Education, a working paper prepared for the National Conference on Preventive Medicine,23 and other studies appearing in this issue of Health Education Monographs.

\section{Sources of Supply of Health Education Manpower}

Since information on health education manpower has been collected from many different groups - including professional associations, public agencies, and other organizations - and from individuals in universities and colleges pursuing advanced studies, a very wide assortment of survey data, membership counts, and professional estimates provide the baseline data on supply and sources of supply.

According to a 1974 survey of institutions offering specialization in health education conducted by Kirk for the Association for the Advancement of Health Education, there were 179 colleges and universities in 41 states offering major programs in health education. ${ }^{1}$ This is in contrast to the 104 institutions in 31 states that were reported in a similar, earlier survey by Sliepcevich in $1970 .^{25}$

Almost all of the increase in these listings represents a growth in the number of programs being offered at the baccalaureate level, from 87 
in 1970 to 165 in 1974 , a remarkable change of 89.6 percent. ${ }^{1}$ It is likely, however, that even these numbers represent a slight underreporting, since a National Directory of College and University School and Public Health Educators issued in $1975^{\circ}$ lists additional institutions which are not included in Kirk's 1974 survey.

As a further caveat, one must keep in mind that manpower supply data based on analyses of surveys used to compile directories may be misleading since some institutions offer three levels of preparation and may offer preparation in either or both school and community health education, or combinations of them. The limitations of these secondary sources may be obvious, but until such time as more definitive studies are done and reporting systems developed, there will still be a lot of professional guess work about institutions preparing individuals for health education work. What is clear, however, is that the reported number of programs at the baccalaureate level has increased dramatically within the last five years. By way of contrast, the number of programs at the master's and doctoral levels has increased, but at a much slower pace, while more institutions are beginning to offer programs in community health or community health education.

Schools of public health and programs in community health education, previously accredited by APHA and now accredited by the Council on Education for Public Health, account for the bulk of health education specialists prepared at the master's level for work in the community and in the health care system. Accreditation of specialized programs in community health education was initiated by the American Public Health Association as a result of action taken by its Executive Board in October 1967.2 Of the 18 accredited schools of public health, 12 currently have programs for preparation of health education specialists. A survey of all graduates of American schools of public health during 1961-67 indicates that 8.2 percent were graduates of the health education curricula."11 Data for 1961-1971 in a similar survey show that 10.6 percent were enrolled in health education. ${ }^{13}$

From the several sources it would appear that Table 1 below represents a fairly close estimate of the number of institutions offering programs in health education including programs in school health education, community health education or a combination of these.

\section{Current Supply and Losses}

Without a uniform health education manpower data collection system and with a limited account of sources of supply and current production, it is difficult to put other pieces of the manpower puzzle in place. Some data have been collected through various means, nevertheless, that provide an estimate of manpower in the field. 
Kent made an estimate in 1972 of currently available personnel, trained in schools of public health (or other APHA accredited programs) at a master's level or beyond and employed in public health education work, as something under 1100.17 Attrition, for whatever reason, is accounted for in this estimate. Another estimate in 1972-73 of 2,000 to $3,000^{30}$ by the Public Health Service probably takes into account personnel trained in health education at the master's level or beyond in institutions other than schools of public health or APHA accredited programs, but excludes "health information specialists" or science writers. While the 1100 figure is documented, the 2,000-3,000 figure is not. Additionally, an Ad Hoc Task Force on Professional Health Manpower for Community Health Programs convened in early 1973 projected the current supply of professionally employed public

\section{TABLE 1}

NUMBER OF COLLEGES AND UNIVERSITIES OFFERING PROGRAMS LEADING TO BACCALAUREATE, MASTER'S OR DOCTORAL DEGREES IN HEALTH EDUCATION 1975

\begin{tabular}{|c|c|c|c|}
\hline & \multicolumn{2}{|c|}{ Number of Institutions offering programs* } & \multirow[t]{2}{*}{ Total } \\
\hline & $\begin{array}{l}\text { School Health } \\
\text { Education }\end{array}$ & $\begin{array}{l}\text { Community Health, } \\
\text { Community Health Education, } \\
\text { or Public Health Education }\end{array}$ & \\
\hline Baccalaureate only & 70 & 14 & 84 \\
\hline $\begin{array}{l}\text { Baccalaureate and } \\
\text { Master's }\end{array}$ & 60 & 9 & 69 \\
\hline $\begin{array}{l}\text { Baccalaureate, Master's } \\
\text { and Doctoral }\end{array}$ & 27 & 4 & 31 \\
\hline Master's only & 7 & 17 & 24 \\
\hline $\begin{array}{l}\text { Master's and } \\
\text { Doctoral }\end{array}$ & 7 & 5 & 12 \\
\hline Doctoral only & 1 & 0 & 1 \\
\hline \multirow[t]{2}{*}{$\begin{array}{l}\text { Specialist } \\
\text { degrees (6 yrs.) }\end{array}$} & 3 & 0 & 3 \\
\hline & 175 & 49 & 224 \\
\hline \multicolumn{4}{|c|}{$\begin{array}{l}\text { *There is some overlap in the first two columns, since a few institutions offer programs } \\
\text { in both school health education and community health or community or public health edu- } \\
\text { cation. This table is known to under-report some institutions that did not respond in time } \\
\text { for publication in sources listed. }\end{array}$} \\
\hline \multicolumn{4}{|l|}{ Sources of data: } \\
\hline \multicolumn{4}{|c|}{$\begin{array}{l}\text { 1. AAHE Directory of Institutions Specializing in Health Education. In School Health } \\
\text { Rev, September/October } 1974 \text {. } \\
\text { 2. Eta Sigma Gamma: A National Directory of Colleges and University School and Pub- } \\
\text { lic Health Educators. Muncie, Indiana, Ball State University, } 1975 \text {. } \\
\text { 3. Schools of Public health in the USA and Canada and graduate programs in com- } \\
\text { munity health education accredited by the American Public Health Association. Am } \\
\text { J Public Health } 64: 2 \text {, February } 1974 \text {. }\end{array}$} \\
\hline
\end{tabular}


health educators at 2,000 . The Task Force based its projection on the estimate that 1,800 health educators* had been graduated from accredited masters level programs up to $1970 .^{13}$

Estimates on currently available personnel, trained at the bachelor's level or beyond with a major specialization in health education in a setting other than a school of public health, are virtually nonexistent. Most persons trained in such programs enter school health education work. An estimate of the number of school health educators employed in 1971 is $20,000^{30}$ but the statistic is not documented and likely includes personnel employed in school health education who have not been professionally prepared with a major specialization in health education. The American Alliance for Health, Physical Education, and Recreation reported approximately 4,000 members as citing school health education as their primary field, ${ }^{30}$ which is close to the membership in a newly organized, autonomous, but affiliated, professional organization, the Association for the Advancement of Health Education. ${ }^{7}$ In assessing this figure, it should be kept in mind that members who indicate health education as a primary field have not necessarily received their professional training with a major specialization in health education. The American School Health Association reported 8,000 members who were school health educators in $1971,{ }^{30}$ but this group also includes personnel trained in nursing and other disciplines.

While an aggregate estimate of 25,000 has been made for all personnel currently employed in health education, ${ }^{20}$ the figure has no published documentation. The data from all sources suggest that so large a figure is erroneous if health education manpower is defined as degree graduates of programs with a specialization in health education in colleges, universities and graduate schools of public health. This 25,000 figure is likely based on membership information more than anything else. Such membership information is frequently inaccurate. For one such estimate provided by the American Public Health Association indicating that in 1971 there were 2,000 public health educators, ${ }^{31}$ it is likely that the estimate was based on membership within the Public Health Education Section of APHA and in the Society for Public Health Education rather than on any survey of the field itself. The figure of 25,000 used by the President's Committee on Health Education likely includes 20,000 individuals reported as members of the then American Association for Health, Physical Education, and Recreation.

* Note: This figure uas determined by taking the total number of degrees awanded American health educators through $1964(1,230)$ reported by Kent and the total number of health educators graduated from American and Canadian Schools of Public Health in the period $1960-1970$ (1,251, an uncited figure), and by making appraximate corrections for the overlap of years and non-American graduates. 
The only data on current manpower supply, therefore, that appear to have any real validity are the data estimates of 2,000 trained public health educators, but it is suspected that it represents a repeated use of an organizational membership base rather than anything else.

What sort of employment growth has there been between the $1950 \mathrm{~s}$ and the 1970s? Data are limited, but from a survey done of health manpower resources, the employment growth of public health educators is reported in comparison with other health occupations. ${ }^{4}$ From Table 2 it would appear that public health educators have consistently represented .05 percent of the total health manpower in about the last 20 years. An estimated increase of 54 percent is cited for the decade 1950-60 and an increase of 75 percent for the decade 196070. In this study, however, sources for employment and employment data are not given. Therefore, there is no way of ascertaining whether actual losses or projected losses are taken into account. Further it is not known whether individuals were professionally prepared in health education. For example, a survey of a variety of health agencies in 1964-65 by the Steering Committee on Health Education of the Association of Schools of Public Health showed that 1309 positions were held by persons not required to have the MPH/MSPH degree. ${ }^{3}$

Data on losses or attrition from the profession as a whole are meager. Kent extrapolates from her data 17 the fallout and attrition rates for personnel holding MPH/MSPH degrees for the period 19441971 in order to make the estimate for present manpower professionally active as shown in the accompanying Table 3. From the Ad Hoc Task Force on Professional Health Manpower for Community Health Programs, projected losses for the decade 1970-1980 assume a one percent annual attrition for new graduates in health education from accredited programs, and 1.5 percent for those employed in $1970 .{ }^{13}$ These projected losses are based on data provided by Kent in a 1966 followup study of the 402 Americans earning a master's degree in health education at the University of North Carolina from 1943 through August 1966. Of the 320 on whom information could be obtained, nine were deceased, 46 were "retired" (usually women with small children), and 31 were in a field considered outside of, but related to, health education. These 86 public health educators represented 26.9 percent of the 320 for whom information was available. The true loss rate is probably significantly higher since information was not available on $82 .{ }^{13}$

Efforts to estimate professional growth and current supply, at least for MPH/MSPH health education specialists, have been made through matriculation data in schools of public health and programs in community health education accredited by the American Public Health Association. In Table 3 Kent shows 1,685 MPH/MSPH graduates in health education between 1944 and 1971, with 455 for the 


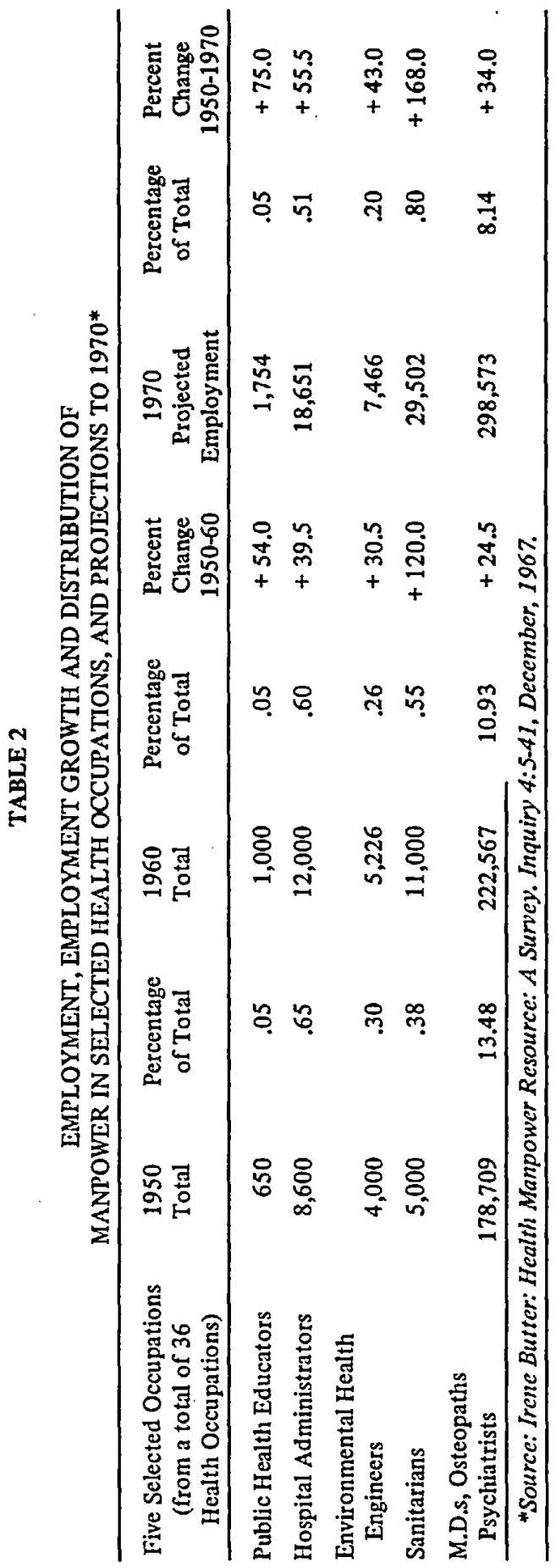


NATIONAL SUPPLY OF M.P.H./M.S.P.H. PUBLIC HEALTH EDUCATORS: FALLOUT AND ATTRITION RATES APPLIED FOR ESTIMATE OF PRESENT MANPOWER PROFESSIONALLY ACTIVE 1944-1971

\begin{tabular}{ccccc}
\hline Years & Graduates & \multicolumn{2}{c}{$\begin{array}{c}\text { Fallout } \\
\text { Rate No. }\end{array}$} & Active Manpower \\
\hline $1944-1964$ & 1230 & $41.5 \% \quad 510$ & 720 \\
$1965-1971$ & $455^{*}$ & & $27.9 \% \quad 127$ & 328 \\
$1944-1971$ & $1685^{*}$ & $\ldots \ldots$ & 637 & 1048
\end{tabular}

Note: These figures are estimates of an Average Training Rate of 65 for each of the last 6 years.

Source: Kent RM: Professional Public Health Education National Manpower. Testimony provided before the President's Committee on Health Education. Atlonta, Georgia, January 27,1972 .

six-year period 1965-1971.

More recently, an April 1975 informal survey of 20 institutions conducted by the Bureau of Health Education of the Center for Disease Control shows the following estimated numbers of students receiving degrees during the period 1971-1975:14

Bachelor's degrees

Master's degrees

Doctoral degrees

It should be noted that these data include foreign students. It is apparent, nevertheless, that the capacity to prepare health education specialists at the master's level has increased dramatically in the last five years. Presumably the health education manpower supply has been proportionately enhanced, but there are, however, no comparative figures to indicate how many of these graduates are employed in health education and, if so, in what capacities.

While Kent's work has certainly been a laudatory and pioneering effort to document the supply of health education manpower, it is now outdated and does not take into account the additional institutions and programs currently offering preparation in health education at the master's level.

\section{Projecting Manpower Requirements in Health Education}

What criteria should be used to project health education manpower requirements over a selected period of time? The answer to this question is complicated not only by changes and developments in the health care delivery system affecting all health personnel, but also in the definition of professional services to be rendered by a trained health educator in various settings.

The earliest projections for health education manpower were made 
in 1945 in the Haven Emerson Report ${ }^{8}$ in which one health educator (presumably MPH/MSPH trained) was recommended for each 150,000 population in local health department units. The Emerson Report pointed out the need for consultant health education services for the minimum sized health unit serving 50,000 .

In the early 1950s, the Society of Public Health Educators recommended one health educator to 9,000 population in its report to the President's Commission on Health Needs of the Nation, ${ }^{13}$ based upon their employment in all agencies, official and voluntary in a given area. In the later 1950s health educators in North Carolina recommended in a report to the World Health Organization that health departments employ one health educator per 25,000 population. ${ }^{15}$ This ratio of one to 25,000 was deemed "reasonable" on the basis of professional judgment and experience.

Kent, using this "reasonable ratio," estimated in 1963 a need for 11,000 health educators for local positions and 44,000 for all positions nationwide by $1980 .{ }^{15}$ Since these figures were estimated on a United States population projection of $275,000,000$ by 1980 , they may now be re-estimated at 9,000 and 36,000 respectively on a revised 1980 census projection of under 225,000,000. In 1972 the Division of Manpower Intelligence, Department of Health, Education, and Welfare, has estimated a need for $4,000 \mathrm{MPH} / \mathrm{MSPH}$ trained health educators by 1980 in addition to those currently employed. ${ }^{32}$ Table 4 shows a projected requirement of 6,000 as compiled by the Task Force on Professional Health Manpower for Community Health Programs in 1973.13

These data appear to relate solely to personnel trained in schools of public health and other accredited programs. Data on projected requirements for personnel trained at the bachelor's level or beyond with a major specialization in health education in a program other than accredited ones are scant. The survey study by the Steering Committee on Health Education of the Association of Schools of Public Health in 1964-65 to determine the number of health educators needed by a variety of agencies by 1970 reported that positions projected for the next five years included an estimated 689 for which the master's degree would be required, and 215 which would not require this degree. ${ }^{3}$ In 1972 , Olsen and Holcomb surveyed state health departments to ascertain the availability of positions for baccalaureate-level health educators. With 43 states responding, 11 reported that they presently employ one or more health educators with a baccalaureate degree, and 20 states indicated they would hire one if such a position were funded. Twenty-eight states indicated that they employ persons as community health educators who have had formal education in areas other than community health.19

Although no adequate assessment of existing vacancies exists for 
health education manpower, it is evident from a recent study of job offerings in the Joumal of the American Public Health Association that MPH/MSPH health educators are among the most frequently sought after professionals in the field, following medical health officers, public health nurses, and health planners. ${ }^{13}$

Although it is difficult at present to describe the quantities of health education manpower available, it is even more difficult to describe those that will be needed in the future. From a quantitative standpoint, there is no clear formula or ratio that indicates that one health educator is needed for " $x$ " population. Efforts to develop ratios have not been very productive to date, since job functions have changed over time; the kinds of agencies employing health educators have changed; and the numbers and kinds of individuals prepared in health education at varying levels who come into the labor market have changed. No ongoing system to monitor the changes has been developed.

At the present time, however, from selected reports of institutions preparing MPH/MSPH public health educators or community health educators, most graduates are finding jobs in the field of health education within three months after graduation. The same may not be said of those in school health education, since declining school enroll-

TABLE 4

HEALTH EDUCATION MANPOWER REQUIREMENTS BY 1980

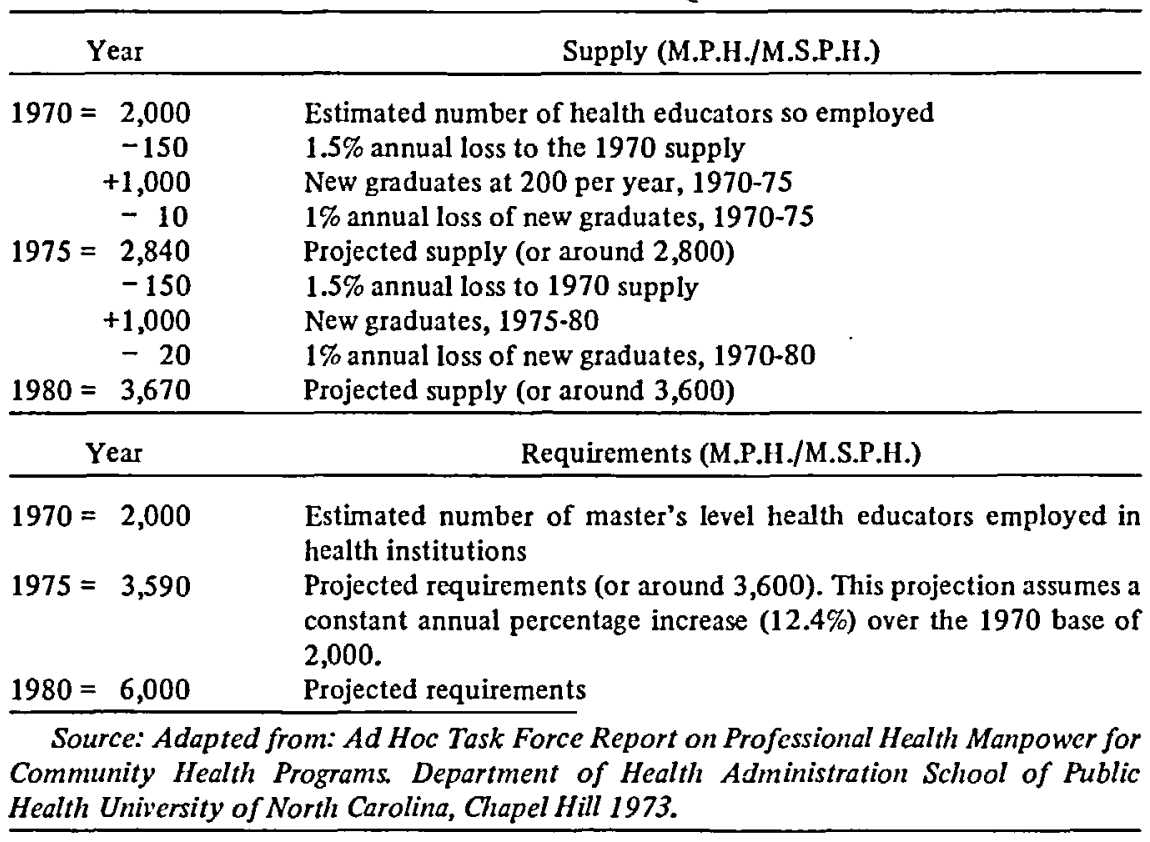


ments and shortage of school tax funds in some areas has reduced demand for school health education manpower.

It is anticipated that the demand for health education manpower within the health care system will continue to grow, however, based on the following developments:

1. Expansion of Hospital-Based Health Education

Adopted by the American Hospital Association in February, 1974 , a major policy statement on personal and community health education provides direction and policy support for the 7,000 member hospitals to develop inpatient, outpatient, staff, and community health education. The statement in fact describes a process which has been underway within hospitals and other health care institutions to provide patient education services on a more comprehensive basis. Further, it reflects major recommendations from the President's Committee on Health Education.

2. Provision of Reimbursement for Health Education from Third Party Payers.

A position statement on reimbursement for patient education has been released by the Blue Cross Association, and it is anticipated that.similar proposals for reimbursement will be developed in the Health Insurance Council and Federal health care programs.

3. Inclusion of Health Education in Legislation for Health Maintenance Organizations.

Although HMO's have been somewhat slow to develop after the Federal legislation was approved and implemented, it is clear in their mandates that they must provide educational services to their members. In truth, few activities are more important and integral to the concept of an HMO than health education which is aimed at life style changes and effective use of health services.

4. Increase in Fedenal Support for Health Education Through Forward Plan for Health 1976-81.

The requirements for expanded health education services in the federal strategy for improved health over the next five years are quite clear in the Forward Plan. Linked as it is to basic concepts of prevention, health education has taken its place as a major tool of health care providers and planners.

5. Development of a National Center for Health Education

Emerging from the recommendations of the President's Committee on Health Education was the stated need for a national focal point in the private sector to provide leadership in health education on a national basis. The Center has been formed and is well on its way to becoming an important national force for health education.

6. Emerging Federal Legislation Emphasizing Health Education 
Public Law 93-641 known as the National Health Planning and Resources Act of 1974 inaugurates a new systems approach to health care planning, and has built health education into the basic ten priorities for the regional planning bodies that are developing. The requirements for a systems approach to planning for health education on a regional basis will strengthen existing programs and create additional programs and services. The National Disease Control and Consumer Health Promotion Act of 1975, SR 99-330, provides a clear indication that the U.S. Senate proposes to expand health education services.

Thus, in addition to employment vacancies known to exist at the present time, vacancies likely to occur due to natural attrition in the field, and job opportunities that will open up in programs and services already under expansion and redevelopment through existing legislative authority, there are six areas of policy at the national level that point to an increased demand for health education manpower in the next few years. These trend-setting events, therefore, make it clearer why the National Conference on Preventive Medicine adopted the following statement and recommendation in 1975: "The shortfall of health education specialists is extreme. These personnel provide leadership in the development of educational methods and programs aimed at improved health care and health-related behavior. [It is recommended] that the federal government takes steps immediately to increase the training capacities for [health education] by one-third, to be accomplished by 1980 at the latest, with further increases to await results of more detailed studies of requirements." 28

The awareness of the shortfall in health education manpower and the need to examine ways to correct it were also reflected in another recommendation from the National Conference on Preventive Medicine to the effect, "that the Secretary of Health, Education, and Welfare arrange for the conduct of a study or studies of consumer health education manpower, to determine current and future needs for all categories and levels of personnel and to recommend appropriate educational and credentialling policies." 27 The latter recommendation is directed not only at considerations of health educators specifically prepared in health education programs, but also at the needs in all health care disciplines for individuals to be prepared in health education.

These recommendations of the National Conference on Preventive Medicine followed closely on the following recommendation made at a Conference on the Federal Focus on Health Education:

"The long neglect in support of health education has created overwhelming need for manpower development. In addition, the present high expectations for the contribution health education can make to the solution of health problems and 
the enhancement of the general well-being of the population is creating an increased demand for service. Therefore inservice education and mid-career training of many existing practitioners are required, as well as the preparation of a large cadre of well-trained health education workers at all levels." 24

In light of the foregoing national policy trends and conference recommendations, two conclusions seem clear. First, that in spite of the inadequacies of existing data, there is a general awareness in many quarters that more health education workers are needed. Second, the projected requirements of 6,000 health education specialists by 1980 (an increase of 4,000 over the estimated existing 2,000 made by HEW Bureau of Health Manpower Education in 1972 and the North Carolina Ad Hoc Task Force in 1973) are probably inadequate.

\section{Some Future Directions}

There are several possible directions for the study of health education manpower, some of which are outlined elsewhere in this issue of Health Education Monographs. Among these is to begin with the source of supply-the "pipeline." An organization associated with the profession needs to undertake responsibility for a process to secure a current and valid list of college and university programs producing health education manpower and the numbers that are produced at each level of matriculation on an annual basis. Simultaneously, this process would require the development of more precise definitions of the preparation and classification of individuals emerging from these programs. Then, assuming that the production system remained intact and operated basically in the same way, one could estimate far more precisely the numbers that would be available to enter the job market. It would be necessary to determine how many of these persons actually enter the occupational field and how many are separated from it. Such a study of the sources of supply, however, is probably the easiest of the studies needed.

Perhaps the next most difficult study to be undertaken is the assessment of the numbers of health education personnel currently employed. This is more difficult because it requires a clearer delineation or classification of personnel by basic preparation and/or job functions. Because the health education field is expanding rapidly and individuals with health education preparation are able to take many different kinds of jobs in the health care system, there is a need for a series of strict definitions to describe functions. Elsewhere in this issue the steps taken to analyze functions are described. Because of shortages of individuals trained in health education, many agencies employ individuals as health educators who are not so prepared, or 
who have only minimum preparation. Without some "cut off" point, i.e. licensure, certification, or graduation from an accredited program, a clear definition of qualified health educators is problematic.

Obviously, the most difficult part of a manpower planning system in health education is the study of current and future demand. Analysis of job vacancies, the time it takes to get a job after graduation, and similar studies all provide some estimate of current demand. Future demand is very obscure, since major legislation and federal programs cause shifts in demand for various personnel in the health care field. This has been particularly true for health educators. One must pose a series of assumptions about the factors influencing demand, and extrapolate from data based on those assumptions. It is in this area that ratios are often used as a kind of short cut. One could use ratios of health educators to population as was done earlier, or ratios of health educators to institutions (i.e. one health educator per hospital over 300 beds), or ratios of health educators to other health care providers and community health workers. In truth, however, there are insufficient data on which to propose ratios at the present time, and it appears that all previous ones were built upon more narrow definitions of functions.

As a matter of collective opinion and some documentation, the need for individuals prepared in health education is increasing. It would thus seem to be a propitious time to begin to provide the documentation and data base to move the occupational category forward through more adequate manpower planning.

\section{REFERENCES}

1. AAHE Directory of Institutions Offering Specialization in Health Education (Survey by Robert Kirk). School Health Rev 5:25-31, September-October, 1974.

2. Boatman RH: Objectives, guidelines, and criteria for the preparation of health education specialists (community) at the master's level. Paper presented at the APHA Annual Meeting, Miami Beach, Florida, October 24, 1967.

3. Boatman RH (Chairman) Steering Committee on Health Education of the Association of Schools of Public Health: Professional preparation in health education in schools of public health. Health Educ Monogr 1 (21):26, 1966.

4. Butter I: Health manpower research: A survey. Inquiry 4:5-41, December 1967.

5. Butter I: Improved statistics are required. J Am Hosp Assoc 46:56-59, 1972.

6. Carnegie Commission on Higher Education: Higher Education and the Nation's Health. Policies for Medical and Dental Education. New York, McGraw-Hill, 1970.

7. Cooper J (Executive Secretary), Association for the Advancement of Health Education: Personal Communication. Washington, D.C., October 1974.

8. Emerson H: Local health units for the nation. New York, The Commonwealth Fund, 1945, pp 2-3.

9. Eta Sigma Gamma: A National Directory of College and University School and Public Health Educators. Muncie, Indiana, Ball State University, 1975.

10. Etzioni A: The Semi-Professions and Their Organization. New York, 'The Free Press, 1969. 
11. Goldston SE, Padilla E: Public health workers in labor force. Health Serv Rep 87:21-23, October 1972.

12. Greenwood E: Attributes of a profession. Soc Work 2:153-161, 1957.

13. Hall $\mathrm{T}$ (Coordinator), Ad Hœ Task Force on Professional Health Manpower for Community Health Programs: Department of Health Administration, School of Public Health. Chapel Hill, North Carolina, University of North Carolina, 1973, pp 113.

14. Henry WD: Personal Communication. June 1975.

15. Kent RM: Public health educators: Study of availability and distribution of alumniwith implications for the profession. Am J Public Health 53:1382-1399 September 1963.

16. Kent RM: Public health educators: Manpower today and the changing scene. Am J Public Health 59:1003-1042, 1969.

17. Kent RM: Professional public health education national manpower. Testimony provided before the President's Committee on Health Education. Atlanta, Georgia, January 27, 1972.

18. Moore W: The Professions: Roles and Rules. New York, Russell Sage, 1970.

19. Olsen LK, Holcomb RA: Utilization of baccalaureate level community health education specialists in state health departments in the United States, 1972. Unpublished document.

20. Report of the President's Committee on Health Education. Washington, D.C., U.S. Dept of Health, Education, \& Welfare, 1973. See also American Medical Association: Allied Med Educ News, July 1, 1973.

21. Ross H (Chairperson) Ad Hoc Task Force on Professional Preparation and Practice in Health Education: Proposed Guidelines for the Professional Preparation and Practice of Health Education Specialists. February 16, 1976.

22. Rugen ME: How We View Our Professional Responsibilities for Health Education. Paper presented at the Public Health Education Section, American Public Health Association, St. Louis, October 28, 1958.

23. Simonds SK: Health education manpower. In Towards a National Policy of Health Promotion and Consumer Health Education: Report of Task Force IV, The National Conference on Preventive Medicine. Bethesda, Md, NIH, Fogarty International Center, June 1975.

24. Simmons J, Skiff AF: Report of The Committee on Manpower Education. Proceedings, Federal Focus on Health Education, Bureau of Health Education, Center for Disease Control, Atlanta, Georgia, June 1974.

25. Sliepcevich EM: Institutions Offering Programs of Specialization in Health Education, unpublished School Health Education study, Washington, D.C., January 1970.

26. Society for Public Health Education and Public Health Education Section, American Public Health Association: Report from Professional Examination Service, Guidelines for Training Entry Level Personnel Performing Health Education Functions, n.d.

27. Task Force on Consumer Health Education: National Conference on Preventive Medicine, Toward a National Policy on Health Promotion and Consumer Health Education. Bethesda, MD, NIH, Fogarty International Center, June 1975, p 156.

28. Task Force on Education and Training of Health Manpower for Prevention. National Conference on Preventive Medicine: Bethesda, MD, NIH, Fogarty International Center, June 1975, pp 129-130.

29. U.S. Department of Health, Education, and Welfare: Health Resources Statistics. PHS Publication no 72-1509, 1971, pp 405-412.

30. U.S. Department of Health, Education, and Welfare: Health Resources Statistics, 1972.1973. DHEW Publication no (HSM) 73-1509. Washington, D.C., Public Health Service, 1973, p 159. 
31. U.S. Departrient of Health, Education, and Welfare: The Supply of Health Manpower - 1970 Profiles and Projections to 1990. DHEW Publication no (HRA) 75-38. Rockville, Md, Bureau of Health Resources Development, 1974.

32. U.S. Department of Health, Education, and Welfare: Provisional Estimates. Washington, D.C., PHS, Bureau of Health Manpower Education, Division of Manpower Intelligence, 1972.

33. Weiss JH: A job classification scheme for health manpower. Health Serv Res 3:4864, Spring 1968. 